\title{
Phosphates as Lithium-Ion Battery Cathodes: An Evaluation Based on High-Throughput Ab Initio Calculations: Supplementary information
}

\section{Stability of the ICSD lithium phosphate containing phases}

Table 2 shows the stability data for the ICSD entries containing at least Li, P, O and a redox active element and without partial occupancies. It is surprising to see so few hydrated phases (only $\mathrm{Li}_{2} \mathrm{Mn}_{2}\left(\mathrm{P}_{6} \mathrm{O}_{18}\right)\left(\mathrm{H}_{2} \mathrm{O}\right)_{10}$ ) but the 9 other Li-M-P-O-H phases in the ICSD, with $\mathrm{M}$ as a redox active element, have missing $\mathrm{H}$ or partial occupancies. 


\begin{tabular}{|c|c|c|c|}
\hline ICSD number & formula & space group & energy above the hull ( $\mathrm{meV} / \mathrm{at})$ \\
\hline 240269 & $\mathrm{Li}_{2} \mathrm{~V}_{2}\left(\mathrm{PO}_{4}\right)_{3}$ & $\operatorname{Pbcn}(60)$ & 0 \\
\hline 25834 & $\mathrm{LiMnPO}_{4}$ & Pnma(62) & 0 \\
\hline 2808 & $\mathrm{LiCu}\left(\mathrm{PO}_{3}\right)_{3}$ & $\mathrm{P} 2_{1} 2_{1} 2_{1}(19)$ & 0 \\
\hline 39534 & $\mathrm{LiTiO}\left(\mathrm{PO}_{4}\right)$ & Pnma(62) & 0 \\
\hline 50588 & $\mathrm{Li} 2 \mathrm{Ni}\left(\mathrm{PO}_{4}\right) \mathrm{F}$ & Pnma(62) & 0 \\
\hline 56291 & $\mathrm{LiFePO}_{4}$ & Pnma(62) & 0 \\
\hline 63509 & $\mathrm{LiFeP}_{2} \mathrm{O}_{7}$ & $\mathrm{P} 2{ }_{1}(4)$ & 0 \\
\hline 68522 & $\mathrm{LiMoP}_{2} \mathrm{O}_{7}$ & $\mathrm{P} 22_{1}(4)$ & 0 \\
\hline 80613 & $\mathrm{LiVO}\left(\mathrm{PO}_{4}\right)$ & Pnma(62) & 0 \\
\hline 81074 & $\mathrm{LiMo}\left(\mathrm{PO}_{4}\right)_{2}$ & $\mathrm{P} 2{ }_{1} / \mathrm{c}(14)$ & 0 \\
\hline 83662 & $\mathrm{Li}_{2} \mathrm{Ni}_{3}\left(\mathrm{P}_{2} \mathrm{O}_{7}\right)_{2}$ & $\mathrm{P} 2{ }_{1} / \mathrm{c}(14)$ & 0 \\
\hline 83832 & $\mathrm{Li}_{1} \mathrm{Sn}_{2}\left(\mathrm{PO}_{4}\right)_{3}$ & $\mathrm{R} \overline{3}(148)$ & 0 \\
\hline 84703 & $\mathrm{Li}_{2} \mathrm{Na}(\mathrm{MoO})_{2}\left(\mathrm{PO}_{4}\right)_{3}$ & $\mathrm{C} 2 / \mathrm{c}(15)$ & 0 \\
\hline 84943 & $\mathrm{Li}_{3}\left(\mathrm{Mo}_{3} \mathrm{O}_{5}\left(\mathrm{PO}_{4}\right)_{3}\right)$ & $\mathrm{P} 2_{1} / \mathrm{c}(14)$ & 0 \\
\hline 93021 & $\mathrm{LiVP}_{2} \mathrm{O}_{7}$ & $\mathrm{P} 2{ }_{1}(4)$ & 0 \\
\hline 94538 & $\mathrm{LiCa}_{9} \mathrm{Mn}\left(\mathrm{PO}_{4}\right)_{7}$ & $\mathrm{R} 3 \mathrm{c}(161)$ & 0 \\
\hline 95979 & $\mathrm{Li}_{1} \mathrm{Ti}_{2}\left(\mathrm{PO}_{4}\right)_{3}$ & $\mathrm{R} \overline{3} \mathrm{c}(167)$ & 0 \\
\hline 98362 & $\mathrm{Li}_{3} \mathrm{~V}_{2}\left(\mathrm{PO}_{4}\right)_{3}$ & $\mathrm{P} 22_{1} / \mathrm{c}(14)$ & 0 \\
\hline 402760 & $\mathrm{LiNiPO}_{4}$ & Pnma(62) & 1 \\
\hline 51212 & $\mathrm{Li}_{2} \mathrm{Ba}_{3} \mathrm{Cl}_{2}(\mathrm{MoO})_{4}\left(\mathrm{PO}_{4}\right)_{6}$ & $\mathrm{P} 22_{1} 2_{1} 2_{1}(19)$ & 1 \\
\hline 62244 & $\mathrm{Li}_{3} \mathrm{Fe}_{2}\left(\mathrm{PO}_{4}\right)_{3}$ & $\mathrm{P} 22_{1} / \mathrm{c}(14)$ & 1 \\
\hline 82383 & $\mathrm{LiNi}_{2}\left(\mathrm{P}_{3} \mathrm{O}_{10}\right)$ & $\mathrm{P} 2{ }_{1} / \mathrm{m}(11)$ & 1 \\
\hline 50958 & $\mathrm{Li}_{9} \mathrm{Fe}_{3}\left(\mathrm{P}_{2} \mathrm{O}_{7}\right)_{3}\left(\mathrm{PO}_{4}\right)_{2}$ & $\mathrm{P} \overline{3} \mathrm{c} 1(165)$ & 2 \\
\hline 51632 & $\operatorname{LiMn}\left(\mathrm{PO}_{3}\right)_{3}$ & $\mathrm{P} 2_{1} 2_{1} 2_{1}(19)$ & 2 \\
\hline 72485 & $\mathrm{Li}_{2} \mathrm{CuP}_{2} \mathrm{O}_{7}$ & $\mathrm{C} 2 / \mathrm{c}(15)$ & 2 \\
\hline 82205 & $\mathrm{LiMo}_{2} \mathrm{P}_{2} \mathrm{O}_{11}$ & $\mathrm{P} 2_{1} / \mathrm{m}(11)$ & 2 \\
\hline 69346 & $\mathrm{Li}_{3} \mathrm{Fe}_{2}\left(\mathrm{PO}_{4}\right)_{3}$ & $\operatorname{Pbcn}(60)$ & 4 \\
\hline 20610 & $\mathrm{LiFeP}_{3} \mathrm{O}_{9}$ & $\mathrm{P} 22_{1} 2_{1} 2_{1}(19)$ & 5 \\
\hline 83582 & $\mathrm{LiCo}_{2} \mathrm{P}_{3} \mathrm{O}_{10}$ & $\mathrm{P} 2{ }_{1} / \mathrm{m}(11)$ & 5 \\
\hline 95973 & $\mathrm{Li}_{3} \mathrm{Fe}_{2}\left(\mathrm{PO}_{4}\right)_{3}$ & $\mathrm{R} \overline{3}(148)$ & 6 \\
\hline 79018 & $\mathrm{Li}\left(\mathrm{Mo}_{2} \mathrm{MoP}_{3} \mathrm{O}_{16}\right)$ & $\mathrm{P} \overline{1}(2)$ & 8 \\
\hline 20537 & $\mathrm{LiVO}\left(\mathrm{PO}_{4}\right)$ & $\mathrm{P} \overline{1}(2)$ & 9 \\
\hline 97767 & $\mathrm{LiNiPO}_{4}$ & $\operatorname{Cmcm}(63)$ & 9 \\
\hline 96964 & $\mathrm{Li}_{1} \mathrm{~V}_{2}\left(\mathrm{PO}_{4}\right)_{3}$ & $\mathrm{P} 2_{1} / \mathrm{c}(14)$ & 11 \\
\hline 97766 & $\mathrm{LiFePO}_{4}$ & $\operatorname{Cmcm}(63)$ & 15 \\
\hline 73868 & $\mathrm{Li}_{2} \mathrm{VP}_{2} \mathrm{O}_{6}$ & $\operatorname{Pna}_{1}(33)$ & 17 \\
\hline 400625 & $\mathrm{LiCoPO}_{4}$ & Pnma(62) & 37 \\
\hline 2149 & $\mathrm{LiCuP}_{3} \mathrm{O}_{9}$ & $\mathrm{P} \overline{1}(2)$ & 52 \\
\hline 65761 & $\mathrm{Li}_{2} \mathrm{Mn}_{2}\left(\mathrm{P}_{6} \mathrm{O}_{18}\right)\left(\mathrm{H}_{2} \mathrm{O}\right)_{10}$ & $\mathrm{P} \overline{1}(2)$ & 419 \\
\hline
\end{tabular}

Table 2: Computed Stability at 0K for the known ICSD compounds containing lithium, a redox active metal, phosphorus and oxygen. An energy above the hull indicates thermodynamic stability at $0 \mathrm{~K}$. A positive number indicates a driving force to transform to other phase(s). 


\section{Relative stability of $\mathrm{LiCoPO}_{4}$ phases with different functionals}

Table 3 shows the calculated differences in the energy per atom between the olivine and LISICON phases of $\mathrm{LiCoPO}_{4}$ for various functionals. Regardless of the functional, the calculated energy per atom of the olivine phase is significantly higher than that of the LISICON phase. Hence, DFT in the GGA, GGA $+U$ and HSE06 approximations predict the LISICON phase to be the ground state, rather than olivine. All computations present in the table are in ferromagnetic states. Antiferromagnetic states have been computed for the olivine structure for $\mathrm{GGA}+\mathrm{U}(\mathrm{U}=3.4 \mathrm{eV})$ and found to be $3 \mathrm{meV} /$ at higher in energy than the ferromagnetic state. For $\mathrm{U}=5.7 \mathrm{eV}$, the AFM state is $1 \mathrm{meV} /$ at lower than the FM state for olivine.

\begin{tabular}{|c|c|}
\hline Functional & Difference in energy olivine versus LISICON $\left(\mathrm{E}_{\text {olivine }}-\mathrm{E}_{\mathrm{LISICON}}\right)$ \\
\hline GGA & $38 \mathrm{meV} /$ at \\
\hline GGA $+U(U=3.4 \mathrm{eV})$ & $34 \mathrm{meV} / \mathrm{at}$ \\
\hline $\mathrm{GGA}+U(U=5.7 \mathrm{eV})$ & $24 \mathrm{meV} / \mathrm{at}$ \\
\hline HSE06 & $25 \mathrm{meV} / \mathrm{at}$ \\
\hline
\end{tabular}

Table 3: difference in energies per atom for the $\mathrm{LiCoPO}_{4}$ olivine and LISICON structures and for different functionals.

\section{ANOVA analysis of the factors determining the voltage}

All the analysis were run using Matlab 7.11.0584 and the "anovan" function.

\section{Redox couple and prototype ANOVA}

The prototype variable was modeled as a random effect. Results for the $2+/ 3+, 3+/ 4+$ and $5+/ 6+$ couples are res[ectively presented in table 4 , table 5 , and table 6 . The $1+/ 2+$ and $4+/ 5+$ couples present too few data points to be used to draw relevant conclusions.

\begin{tabular}{|c|c|c|c|c|c|c|}
\hline Source & Sum Square & d.f. & Mean Square & F & Prob $>$ F & $\eta^{2}$ \\
\hline \hline redox couple & 111.78 & 7 & 15.97 & 279.85 & $<0.0001$ & 0.66 \\
\hline prototype & 36.82 & 78 & 0.47 & 8.27 & $<0.0001$ & 0.21 \\
\hline error & 8.96 & 157 & 0.057 & & & \\
\hline total & 167.57 & 242 & & & & \\
\hline
\end{tabular}

Table 4: results for the two variables ANOVA analysis on the $2+/ 3+$ couples: redox couple and prototype 


\begin{tabular}{|c|c|c|c|c|c|c|}
\hline Source & Sum Square & d.f. & Mean Square & F & Prob $>$ F & $\eta^{2}$ \\
\hline \hline redox couple & 148.42 & 11 & 13.49 & 376.69 & $<0.0001$ & 0.63 \\
\hline prototype & 67.09 & 69 & 0.97 & 27.15 & $<0.0001$ & 0.29 \\
\hline error & 8.53 & 238 & 0.036 & & & \\
\hline total & 234.36 & 318 & & & & \\
\hline
\end{tabular}

Table 5: results for the two variables ANOVA analysis on the $3+/ 4+$ couples: redox couple and prototype

\begin{tabular}{|c|c|c|c|c|c|c|}
\hline Source & Sum Square & d.f. & Mean Square & F & Prob $>$ F & $\eta^{2}$ \\
\hline \hline redox couple & 29.18 & 6 & 4.86 & 154.62 & $<0.0001$ & 0.47 \\
\hline prototype & 20.42 & 31 & 0.66 & 20.94 & $<0.0001$ & 0.33 \\
\hline error & 0.91 & 29 & 0.031 & & & \\
\hline total & 62.05 & 66 & & & & \\
\hline
\end{tabular}

Table 6: results for the two variables ANOVA analysis on the $5+/ 6+$ couples: redox couple and prototype

The $\eta^{2}$ value estimates the amount of variance that can be explained by the factor.

\section{Effect of the number of links to a phosphate group}

Figure 1 plots the Z-score for the voltage versus the number of PO4 groups linked to the redox active element. The figure does not indicate any clear dependence between the voltage and the number of linked PO4 groups.

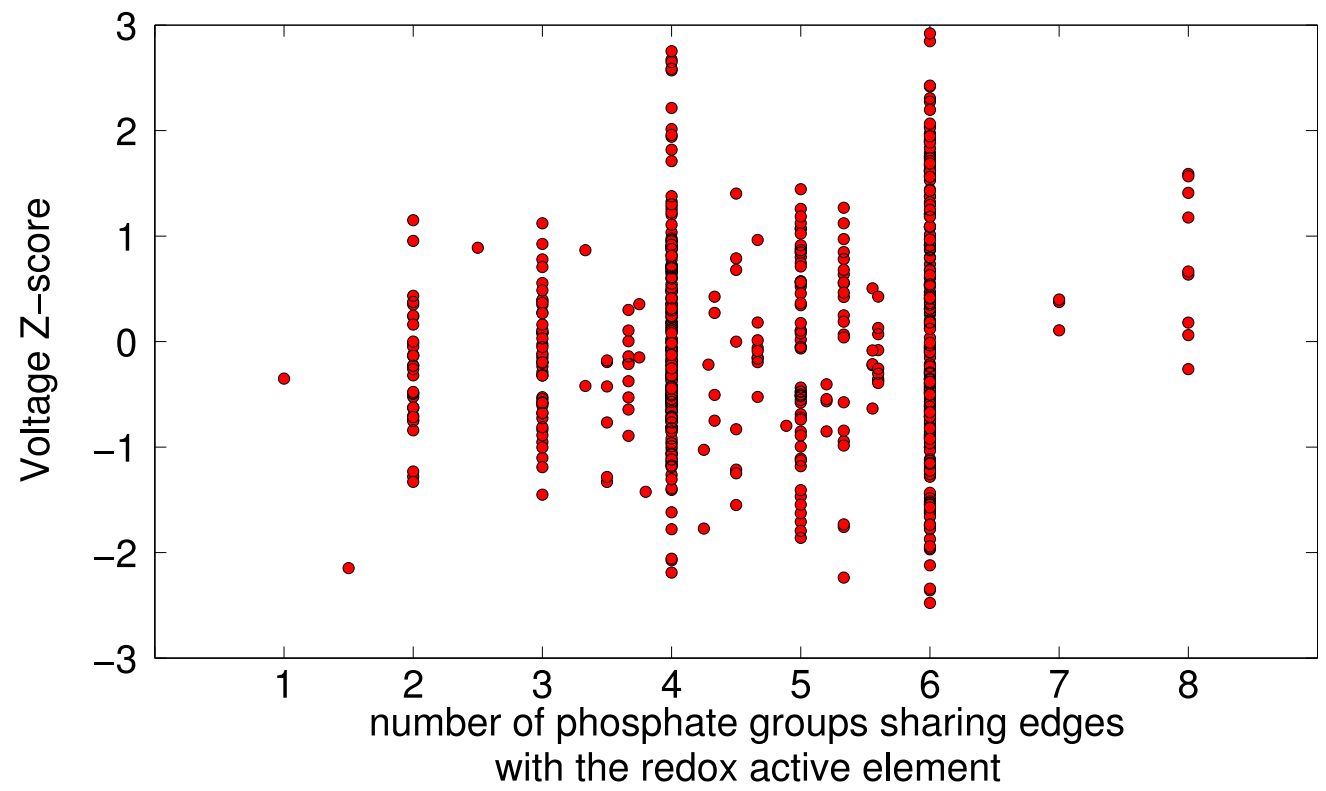

Figure 1: voltage z-score versus number of PO4 groups linked to the redox active element. 
An ANOVA analysis has been run using the redox couple and two continuous variables: the electrostatic voltage and the number of PO4 groups linked to the redox active element. Results are in table 7.

\begin{tabular}{|c|c|c|c|c|c|c|}
\hline Source & Sum Square & d.f. & Mean Square & F & Prob $>$ F & $\eta^{2}$ \\
\hline \hline redox couple & 410.211 & 34 & 12.065 & 80.31 & $<0.0001$ & 0.74 \\
\hline electrostatic & 63.06 & 1 & 63.0601 & 419.75 & $<0.0001$ & 0.11 \\
\hline linked PO4 & 2.561 & 1 & 2.5613 & 17.05 & $<0.0001$ & 0.005 \\
\hline error & 96.299 & 641 & 0.1502 & & & \\
\hline total & 550.705 & 677 & & & & \\
\hline
\end{tabular}

Table 7: results for the three variables ANOVA analysis: redox couple, electrostatic and number of linked PO4 groups.

\section{Effect of the P-O bond length on the voltage}

Figure 1 plots the z-score for the voltage versus the P-O bond length linked to the redox active element. The figure indicates some dependence of this factor with lower P-O bond length associated with higher voltage.

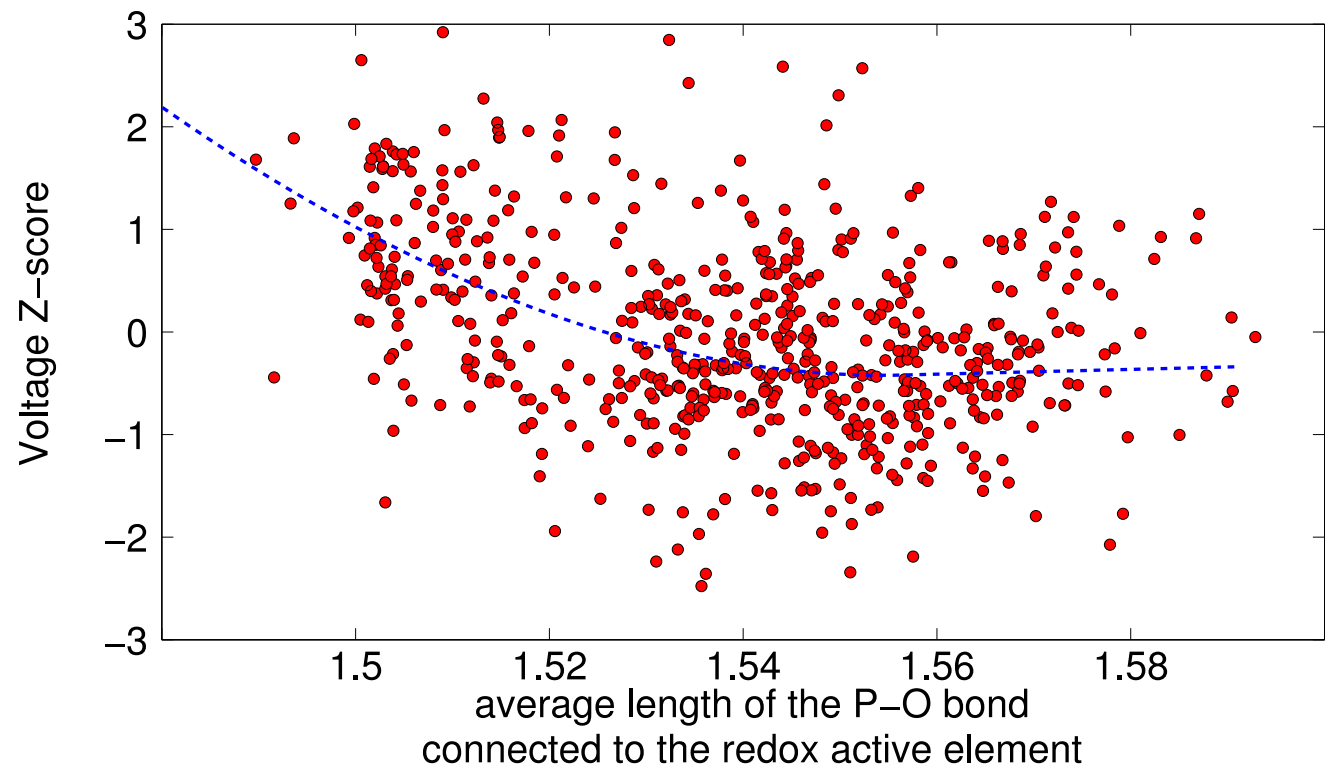

Figure 2: voltage z-score versus $\mathrm{P}-\mathrm{O}$ bond length for oxygens connected also to a redox active element. The blue dashed line is drawn for helping the eye.

An ANOVA analysis has been run using the redox couple and two continuous variables: the electrostatic voltage and the average P-O bond length for oxygen linked to the redox active element. Results are in table 8. 


\begin{tabular}{|c|c|c|c|c|c|c|}
\hline Source & Sum Square & d.f. & Mean Square & F & Prob $>$ F & $\eta^{2}$ \\
\hline \hline redox couple & 407.58 & 34 & 11.9876 & 96.49 & $<0.0001$ & 0.79 \\
\hline electrostatic & 51.729 & 1 & 51.7291 & 416.38 & $<0.0001$ & 0.10 \\
\hline P-O length & 12.076 & 1 & 12.0763 & 97.21 & $<0.0001$ & 0.02 \\
\hline error & 73.547 & 592 & 0.1242 & & & \\
\hline total & 517.251 & 628 & & & & \\
\hline
\end{tabular}

Table 8: results for the three variables ANOVA analysis: redox couple, electrostatic and P-O bond length.

\section{Effect of the Phosphorus to Oxygen ratio on the voltage}

Results are presented in table 9.

\begin{tabular}{|c|c|c|c|c|c|c|}
\hline Source & Sum Square & d.f. & Mean Square & F & Prob $>$ F & $\eta^{2}$ \\
\hline \hline redox couple & 420.23 & 34 & 12.3597 & 106.22 & $<0.0001$ & 0.76 \\
\hline electrostatic & 34.749 & 1 & 34.7487 & 298.63 & $<0.0001$ & 0.06 \\
\hline $\mathrm{P} / \mathrm{O}$ & 24.274 & 1 & 24.2741 & 208.61 & $<0.0001$ & 0.04 \\
\hline error & 74.586 & 641 & 0.1164 & & & \\
\hline total & 550.705 & 677 & & & & \\
\hline
\end{tabular}

Table 9: results for the three variables ANOVA analysis: redox couple, electrostatic and number of linked PO4 groups. 